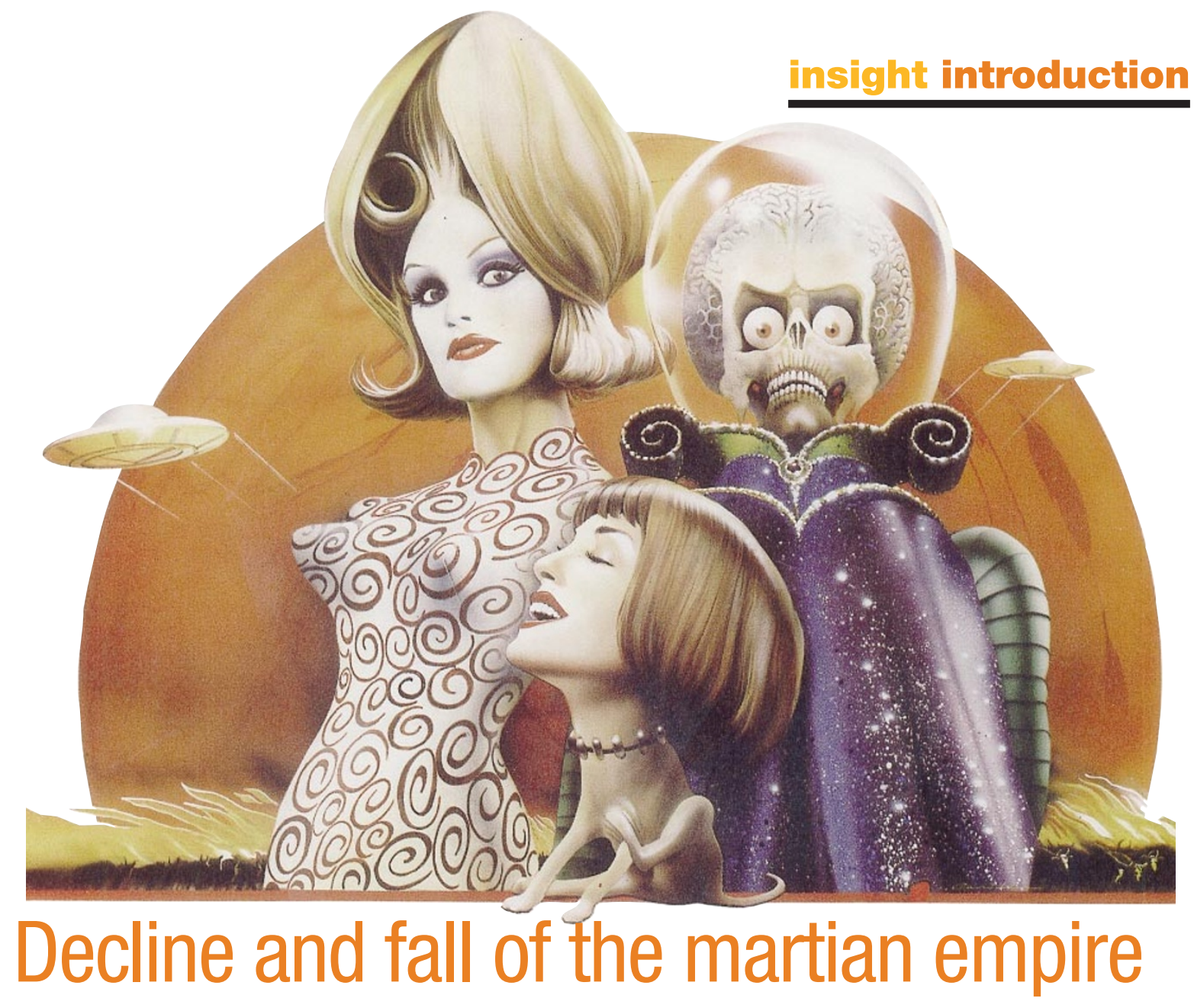

\title{
Kevin Zahnle
}

NASA Ames Research Center, Moffett Field, California 94035-1000, USA

"Are they worlds, or are they mere masses of matter? Are physical forces alone at work there or has evolution begotten something more complex, something not unakin to what we know on Earth as life? It is in this that lies the peculiar interest of Mars."

Percival Lowell (in ref. 1, p. 3)

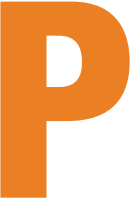

erhaps it was in a Japanese garden that $\mathrm{Mr}$ Percival Lowell, the already well-known American orientalist and travel writer, first understood with the peculiar force of revelation just why the discovery of canals on

Mars was the great event of his time. Perhaps the news had come in the form of wadded newsprint cushioning gifts shipped from home; stories about base ball and canals on Mars wrapping a fruitcake, maybe. One sees Percival, 38 years old and losing his fascination with the East, stepping from stone to stone across a dry sand sea raked to evoke waves on open water and waves lapping the shores of bare rock islands. One sees him distractedly tracing channels in the sand with a stick, drawing geometric patterns. One imagines him forming a plan.

Lowell's peculiar revelation actually took place after he had returned home to Boston in late 1893 to arrange for the publication of Occult Japan, when he received as a Christmas gift Camille Flammarion's La Planète Mars et ses Conditions d'Habitabilité (ref. 2; see also ref. 3, p. 104). In this beautiful and heavily illustrated volume, Flammarion compiled essentially every credible telescope observation of Mars that had been made. He describes a Mars of dry plains and shallow seas, an obviously habitable world, but more important, he also freely speculated of a Mars of canals built by a higher civilization than any ever known on Earth (ref. 2, p. 586). (Oddly, Flammarion himself was never able to see the canals.)

Lowell's latent interest in astronomy had been growing as his interest in Japan waned. He read Flammarion's book "with lightning speed" and scrawled upon it the imperative "Hurry!" $\mathrm{He}$ would need his own observatory, under clear, clean, still air, and quickly. The opposition of Mars in October 1894 would be the last good one for more than a decade.

\section{The canals}

The canali of Mars were discovered in 1877 by Giovanni Schiaparelli using a modest $22-\mathrm{cm}$ refractor in Milan. Schiaparelli had first won fame by showing that the annual Perseid meteor shower was due to comet Swift-Tuttle ${ }^{3}$. This fame earned him his observatory, where he visually measured double stars to high accuracy. Thus his surprising 1877 map of Mars was taken seriously. The wonderfully evocative martian nomenclature (consider, for example, Tharsis, Chryse, Elysium, Amazonis, Trivium Charontis and Syrtis Major) that still survives derives from this map. The canali were at first depicted mostly as broad channels, 


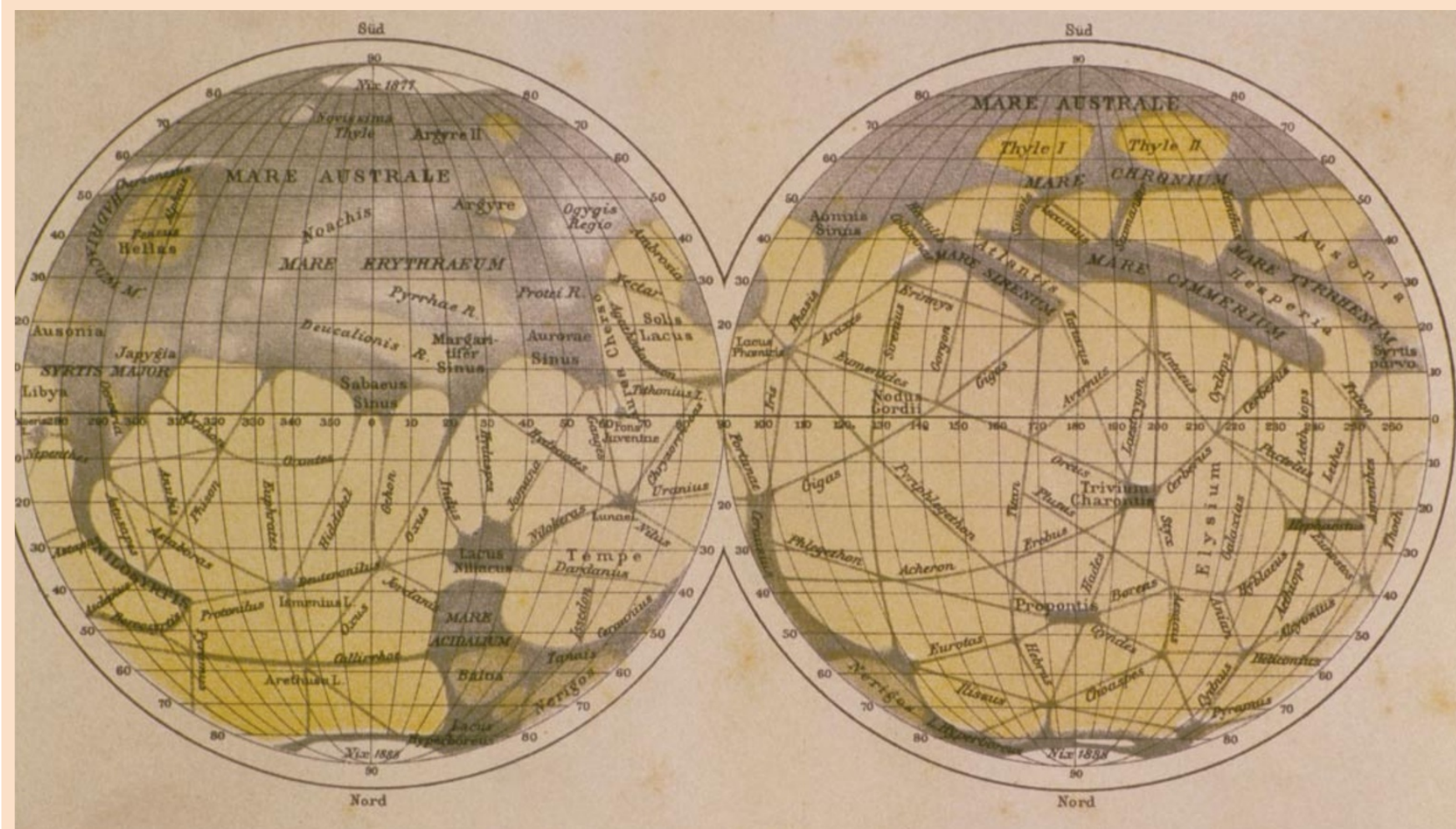

Figure 1 Mapping the surface of Mars. The Italian astronomer Giovanni Schiaparelli made this drawing in the early 1880s. He called the straight surface features canals, and also noticed that the patterns on the surface changed with the martian seasons, which he attributed to seasonal changes in vegetation.

more akin to the Malagasy Strait or the Red Sea than to the thin blue-green lines they were to become. (Schiaparelli's and other early areographies reflect the theory that the dark areas on Mars were seas; W. H. Pickering and Lowell showed the seas to be dry land.) At succeeding and progressively less favourable martian oppositions, Schiaparelli's canali hardened into a geometric network of razorsharp, ruler-straight canals (Fig. 1). Many of the canali also began to appear in pairs, a controversial phenomenon that Schiaparelli referred to as "gemination".

At first, belief in the reality of the canals spread, as ever more observers seemed to glimpse some of what Schiaparelli had seen. In the late 1880s, apparent confirmations came from the world's largest refractors: Perrotin and Thollon in Nice, Schaeberle (and to a lesser extent Holden and Keeler) at Lick Observatory in California. Popular speculation centred on life and who might be living there, and what they might think of us. Signal lights were reported. An 1890 observation of projections towering above the martian limb (later shown to be dust clouds; ref. 4, p. 104) was also interpreted by some in the popular press as evidence of martians signalling Earth. A French widow, Clara Goguet Guzman, established a FFr100,000 ‘Guzman prize' for the person or nation that first succeeded in establishing dialogue with another planet or star (ref. 3, p. 90), although it is said that she "excluded Mars because it would be too easy to establish contact" (ref. 5, p. 74). Later, in an episode preminiscent of the 'Face on Mars', one of Keeler's 1890 drawings of Mars was re-interpreted by the popular press as depicting the Hebrew letters for the name of God "True, the magnitude of the work of cutting the canals into the shape of the name of God is at first thought appalling..." is a quote from the 2 June 1895 edition of the San Francisco Chronicle (ref. 3, p. 88).

A widespread story, perhaps spread by the anti-canalistas as some sort of apocryphal folk justice, is that Schiaparelli went blind. In fact, he lived long and prospered, with the favour of the King. Schiaparelli continued to observe Mars at every opposition until his death in 1910. However, he did not publish his observations of Mars made after 1890 because he regarded his vision as less keen than it had been formerly. More interesting were his coy delphic hints regarding the artificiality, and towards the end of his life, even the very reality, of the canals. His contemporaries were never able to pin him down on the matter.

\section{Lowell}

Enter Percival Lowell. Lowell hired aides through his Harvard connections, including the confirmed canalista W. H. Pickering, and sent A. E. Douglass (who later founded the Steward Observatories at Tucson) to scout about Arizona and Mexico for good air at high elevation ${ }^{6}$. The setting of the Arizona city of Flagstaff on a high forested plateau fit Lowell's preconceptions of where the air would be best, and although in later years he would have cause to doubt his choice, time was of the essence.

The nature of Lowell's quest is revealed by what he said and wrote of the canals in the months before he first trained his new telescopes on Mars. Writing in the Boston Commonwealth on 26 May 1894, Lowell said: "The most self-evident explanation from the markings themselves is probably the true one; namely, that in them we are looking upon the result of the work of some sort of intelligent beings" (quoted by ref. 6, pp. 58-59).

His observatory was built and outfitted with borrowed 12- and 18-inch refractors in time for the martian season. Lowell and colleagues had to train themselves to see the canals (by all accounts they are hard to see, and as there were typically two or three observers who each tried to confirm what the others saw, there were other psychological factors at work), but once they learned how to do it they soon surpassed Schiaparelli's total.

Lowell's brilliant public lectures, his magazine articles, his tireless efforts at popularization that culminated in several books (Mars ${ }^{1}$, published in 1895; Mars and its Canals ${ }^{4}$, published in 1906; and Mars as an Abode of Life ${ }^{7}$, published in 1908; see Box 1), made him and his Mars famous. In my opinion his argument can be reduced to the following essential points. (1) The polar caps are water ice. Here he chooses "between the rival candidates of common sense and uncommon subtlety, water and frozen carbonic acid gas" (ref. 4, p. 39). His key argument apart from "common sense" is the seasonal presence of 
Box 1

Lowell's cosmogony

Lowell wrote three books concerned primarily with Mars: Mars ${ }^{1}$ (1896); Mars and Its Canals ${ }^{4}$ (1906); and Mars as an Abode of Life ${ }^{7}$ (1908). The first bears the lightest touch, and is often marked by good humour. He both opens and closes with the classic arguments of SETI (the Search for Extraterrestrial Intelligence), but in the pages between he presents his case for Mars. He develops the case more fully in Mars and Its Canals. The book opens with an inspiring essay "On Exploration", in which he introduces the metaphor Carl Sagan later used for Cosmos. He divides the rest of the book into four parts: Natural Features, Non-Natural Features, The Canals in Action and Explanation. In this book Lowell shows signs of desperation. Although he is winning in the marketplace of public opinion (for example, The Wall Street Journal ranked “...the proof by astronomical observations...that conscious, intelligent human life exists upon the planet Mars" as one of the chief events of 1907), he is losing ground among scientists. One imagines that doubt gnawed at his sheets, but he betrays no uncertainty apart from less good humour. Large parts of the book are given over to dry observations of the canals, too painful now to read.

In Mars as an Abode of Life, Lowell invents "planetology" and expands on his cosmogony. He begins with nods towards the then fashionable ideas that the Universe consisted mostly of dark matter and that the Sun and its Solar System were born out of a close encounter between two dark stars. But his thoughts were mostly informed by a common sense (or folk science) understanding of surface-to-volume ratio. Worlds were formed hot. Large worlds cooled slowly, and were still evolutionarily young in 1894, "while in the moon we gaze upon the last sad age of decrepitude, a world almost sans air, sans sea, sans life, sans everything" (Lowell writing in the Boston Commonwealth, 26 May 1894; quoted in ref. 6, pp. 58-59). He places the origin of life in a Hadean realm of geothermal heat hidden from the Sun. This view of planetology remains in play.

In Lowell's planetology, worlds dry out as they age. One reason is that air escapes to space (discussed in detail in Mars, pp. 53-57), with the gases of low atomic mass, like water, escaping first. Another reason presumes cooling. "As the [internal] heat dissipates, the body begins to solidify, starting with the crust. For cosmic purposes it undoubtedly still remains plastic, but cracks of relatively small size are both formed and persist. Into these the surface water seeps. With continued refrigeration the crust thickens, more cracks are opened, and more water given lodgement within, to the impoverishment of the seas" (ref. 7, p. 146). Eventually the water that does not escape goes into hiding, leaving the surface a pitiless desert. If such a world still be inhabited, its inhabitants need husband their water. With some updating of his language (read cracking by impact cratering, let planetary cooling be manifest as little or no recycling, and let those inhabitants be our descendants) we obtain a contemporary picture of Mars.

a blue polar collar of meltwater that borders the retreating polar caps. At plausible pressures, dry ice does not liquefy. (2) A "wave of darkening" passes from pole to equator (and beyond) as the polar cap retreats. This is explained as growth of vegetation along canals and in oases as meltwater becomes available to more distant fields. (3) The "canaliform [sic] features" form a network too regular to be natural. Therefore they were constructed by an intelligence not unlike ours, for the purpose of husbanding and distributing scarce water. The aqueducts themselves would be unseen; rather the features represented swaths of irrigated land.

At first, Lowell's canals were received as credible, despite doubts regarding the theory by which he explained them, and despite the difficulty astronomers at Lick Observatory (a better site with a bigger telescope) had in confirming them. His location was good and his

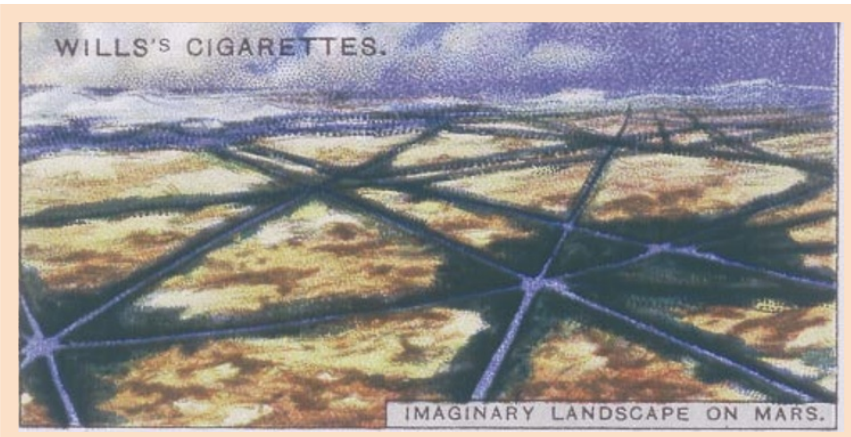

Figure 2 Romance of the Heavens. Included in a cigarette-card set published in 1928 is an image depicting a distinctly Lowellian view of the martian landscape.

instruments were good. But confidence in Lowell fell sharply following his report in 1896 of a spoke-like pattern of linear markings on the surface of Venus ${ }^{6}$. By the opposition of 1907, despite a spectacular publicity campaign by Lowell and his staff featuring photographs of the greatest canals, many of the early canalistas had recanted, including in particular Antoniadi at Meudon, Cerulli at Collurania, and Douglass, his former assistant. Part of the problem was that the canals truly are not there; thus when conditions were especially good for observing them they were least visible. Antoniadi, who had begun as a protégé of Flammarion but with whom he later broke, reported seeing bewildering amounts of detail with Meudon's 33 -inch refractor in 1909, but nothing at all that looked artificial. The rest of the problem was that Lowell's flamboyance, combativeness and inflexibility made him look ever more like a crank (Box 2).

What in fact were Schiaparelli, Lowell and others seeing? In Mars', pp. 145-147, Lowell lists 183 canals on Mars and the number of times each was seen in Flagstaff in 1894-5. The canal most often seen was Agathodaemon. When one compares Lowell's map to modern maps, one finds that Agathodaemon is Valles Marineris; that is, the most often seen canal on Mars coincides with the most prominent real channel on Mars. The second most often seen canal was Daemon, coincident with the chaos at the origin of Valles Marineris. A few other canals also prove real: for example, the double (geminated) canal Gigas corresponds to parallel rifts aligned with the great Tharsis volcanoes. But most of the canals are pure fancy. Lowell once said that "not twenty people in the world have seen them, but the fifteen who have seen them, have seen them." What we seem to have had here was a folie a quinze.

\section{Lowell's legacy}

Pluto bears his name, but Mars is Percival Lowell's planet. By dint of his resources, talent and energy, and most of all by his choosing to "take the popular side of the most popular scientific question about" (W. W. Campbell, quoted by ref. 3 from Campbell's review of Mars in 1896), Lowell defined Mars in the popular imagination for nearly a century. His vision of a habitable and vegetated planet persisted into the space age, while his extreme position on the canals lent cover to those who would dream of a verdant Mars yet wished to think their hopes moderate.

Lowell's legacy reaches us today through two distributaries. One is through the mainstream of science, where the extent of his influence is emphasized by Horowitz ${ }^{8}$. Mid-century observers continued to address the thickness and composition of the martian atmosphere, the nature of the polar caps, the nature of the wave of darkening, and the nature of the dark stuff (that is, is it vegetation?). Because they were working at the edge of their resolution, most of the results they obtained were at the resolution limit. Unfortunately most of the results they obtained were wrong, because most of what they were looking for had signals well below their resolution limits. A brief overview of de Vaucouleurs' The Physics of the Planet Mars ${ }^{9}$ or the 1961 report of the Space Science Board ${ }^{10}$ to NASA shows how badly wrong they were: Mars possessed water-ice polar caps, 85-mbar $\mathrm{N}_{2}$ 


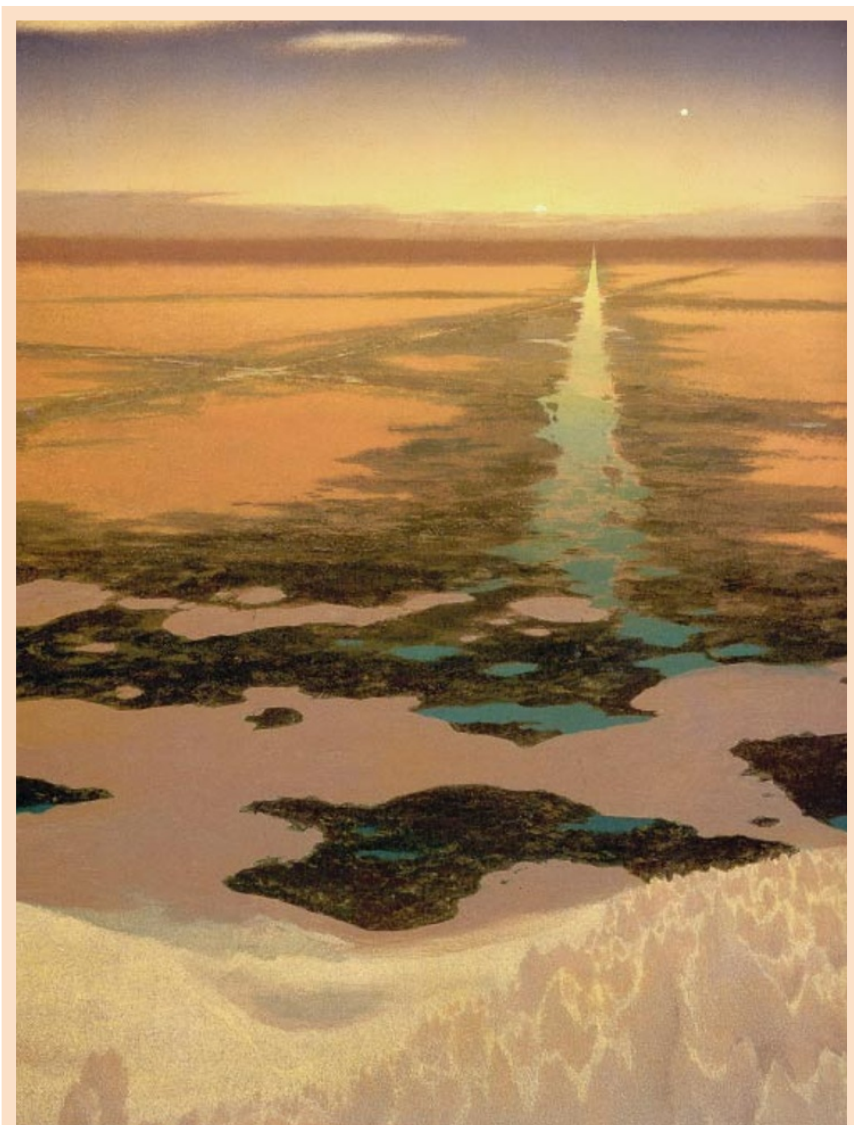

Figure 3 Lowell's legacy flows through popular culture, with martian canals and their builders seizing the public imagination.

atmosphere (unchanged from Lowell), cold but tolerable surface temperatures, and seasonal changes probably due to vegetation. Concerning the polar caps, de Vaucouleurs wrote: "It is hardly necessary to mention that the alternative hypothesis of carbon dioxide snow (dry ice) is no longer tenable" (ref. 9, p. 193). "Infrared reflectance spectra of the polar caps show conclusively that they are not composed of frozen carbon dioxide" is how the Space Science Board put it (ref. 8, p. 86). There was even discussion of martian nuclear weapons tests as the cause of reported flashes ${ }^{11}$.

Although belief in the reality of the canals began to fade even before the turn of the century, with the last credible sightings by Trumpler in 1924 and Fournier and Pettit in 1939, confidence in a vegetative origin for the "wave of darkening" seems to have reached its peak at the dawn of the space age. E. C. Slipher, writing in 1964, was direct: "Not a single thing has been detected that it does not explain. Every year adds to the number of those who have seen the evidence for themselves. Thus theory and observations coincide." The Space Science Board concurred: "The evidence taken as a whole is suggestive of life on Mars. In particular, the response to the availability of water vapour is just what is to be expected of a planet now relatively arid, but which once probably had much more surface water" (ref. 8, p. 90). More measured, but no less Lowellian, was de Vaucouleurs' summary: "we might liken [the physical conditions on Mars] to those which obtain on a terrestrial desert, shifted to the polar regions and lifted to stratospheric level. We leave it to the reader to decide whether under such circumstances Mars can be 'the Abode of Life' or not" (ref. 9, p. 41). Alternatives to vegetation, in particular windblown dust, were offered but seem to have been unpopular (for example, de Vaucouleurs (ref. 9, p. 269) dismisses "the non-vegetative hypothesis" with a few sentences of exposition and two pages of objections), for much the same sort of reasons that Lowell gave for preferring water over frozen carbonic acid gas.
Box 2

Lowell and Wallace

Alfred Russel Wallace, the co-discoverer of evolution by natural selection, was aged 83 in 1907 when he issued his classic response Is Mars Habitable $?^{15}$ Wallace began by accepting the canals as a debating point; he had a deeper purpose. Lowell's arguments were generally much better than Wallace makes them out to be, which is why many survived substantially intact into the 1960s, but Wallace identified three fatal flaws, two in physics, the third in interpretation. In order to justify liquid water and clement climates on Mars, Lowell was forced to argue that Earth's albedo is $75 \%$. Thus Mars, with an albedo of $27 \%$, would be comfortable. Wallace had little doubt that this high albedo was wrong - clouds have albedos less than $75 \%$ and Earth is no more than half cloud-covered.

Nor did Wallace think the colour of the polar collar a strong argument; on the contrary, he thought the argument ridiculously weak. He suspected the meltwater, were it water, to be necessarily shallow, turbid and muddy brown; not blue. Lowell never compared the amount of water in the martian snowfields to the requirements of the canals, but Wallace did. He found that "the water supply is ludicrously inadequate" to justify anything approaching the "over one hundred thousand miles of canals" that Lowell had mapped (ref. 15, p. 26). In the end, Wallace aligned himself with the candidate of uncommon subtlety: the polar caps are dry ice, and temperatures are correspondingly and uncompromisingly low. On these grounds he concluded that Mars is not habitable. With respect to the polar caps, availability of water and surface temperature, Wallace was right. Mars is not in any apparent sense currently habitable.

The deeper argument was with respect to interpretation. Here Wallace answered the "Nothing I can think of apart from life can explain..." or the "I'll know it when I see it" arguments that still pervade the abstract business of life detection, be it in ancient terrestrial rocks, martian meteorites, europan oceans or extrasolar planets. All that is required is to supply a possible counter-example. This Wallace does, in two ways. He closes the book by offering a physical model of fracturing of a cooling, originally hot lithosphere accreted around a primordial cold core. But first he cuts to the quick, by illustrating that different minds can draw different conclusions from the same data. He questions the canals as works of art. Why so straight? (Irrigation canals generally follow the contours of the land, after all.) Is there no topography at all on Mars? How is that possible? What sense is there to this dense network? Where is the design? Why more than 100,000 miles of canals to move such tiny amounts of meltwater? And so on. One is almost bound to agree with him that the canals, "as Mr. Lowell describes, would be the work of a body of madmen rather than of intelligent beings".

Yet around 1963, the imminent launch of the first Mars probes seems to have spurred new work, and with the new work, revisionism. New evidence of a much thinner atmosphere led to new interest in dry ice and a strange suggestion that Mars was coloured by, and sterilized by, abundant nitrogen tetra-oxide (see ref. 12 for a journalist's survey of the then current martian climate). In the end, it was the success of Mariner IV in 1965 that destroyed all hope and smashed all dreams. Mariner IV revealed a heavily cratered moonscape where canaliform features ought to have been. Worse, Mariner IV revealed the dismal truth: "The thinness of the martian atmosphere has been one of the great disappointments of the space age" was how Anders and Owen ${ }^{13}$ opened their landmark study of martian volatile inventories. In this suddenly chilled climate, dry ice leapt back to favour as the chief constituent of the seasonal polar caps ${ }^{14}$. The sense of disappointment is still bitter after 35 years. The word echoes through the pages of To Utopia and Back, Norman Horowitz's excellent history of the Viking programme and its roots in Lowell's 
visions. The reality that Mars is probably dead is still so hard to accept that revivification remains the central thrust of NASA's unmanned planetary exploration programme.

The other great distributary of Lowell's legacy flows through popular culture. Martians and canals established an immediate foothold in the public imagination, with illustrations of martian canals even used to sell cigarettes (Fig. 2; and see ref. 5, p. 74). It was only 12 years ago that the Vice-President of the United States referred publicly to the canals on Mars as fact: "We have seen pictures where there are canals, we believe, and water. If there is water, that means there is oxygen. If oxygen, that means we can breathe." Lowell's Mars was also enlisted by the utopians. Mars was held up as an example of global peace and cooperation, by Lowell and others, for how else could such an intricate system of canals be constructed and maintained? In his tongue-in-cheek explanation (to the arch-Republican Lowell) of his poem 'The Gospel from Mars', E. H. Clement wrote: "My main object is to show that such a system as has developed on Mars, the people of all nations must cease regarding boundary lines and have become one brotherhood, in fact and deed [sic] - so likewise the social classes. In short I am going to show why Mars is carrying through our Heavens the heart-red flag of socialism!" (quoted in ref. 6, p. 220).

A visit to the local science-fiction bookseller reveals an Amazon of hopeful Mars lore flowing underground. H. G. Wells' War of the Worlds, published in 1898, is perhaps the best known early example. It is my belief that this huge aquifer of fictional information is the main source of new hope for the dead planet. I had meant to research some of this fiction. Preliminary findings based on cover art, beginning with Edgar Rice Burroughs, reveal that martians developed silicone implants and photosynthetic skins before earthlings did. Ray Bradbury's Martian Chronicles and Arthur C. Clark's Sands of Mars

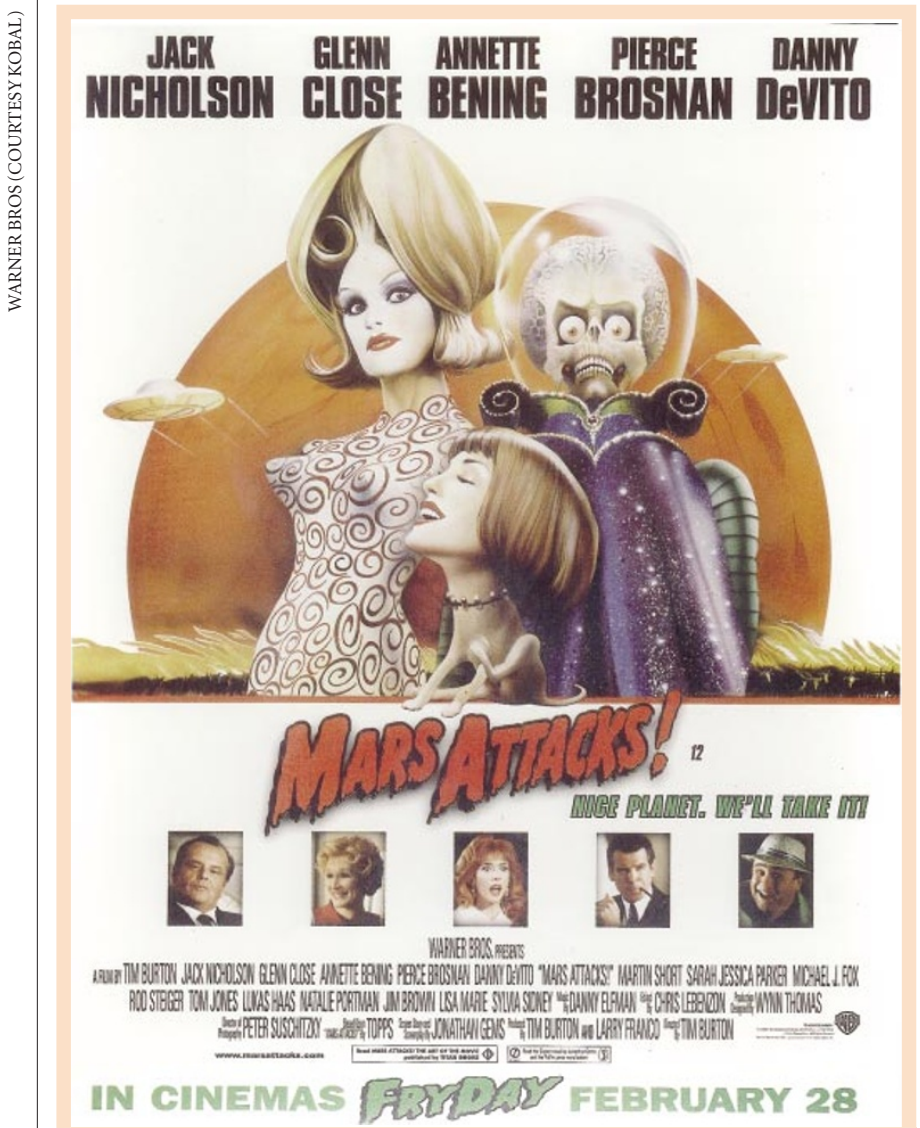

If martian nuclear weapons tests were the cause of observed flashes on Mars in the 1960s, perhaps it was in preparation for a future assault on Earth. have been cited as formative by many space scientists; more recently a rainbow of Mars books (Red, Green, Blue and White; other colours still available) have caught attention among the Mars community. Of the arguably martian novels, my own personal favourites are War of the Worlds and Frank Herbert's Dune (the latter martian only in the sense that it takes place on a profoundly desiccated world that takes its water from the polar caps). What does inspire me are Chesley Bonestell's paintings of unimaginably ancient canals, still greening the martian desert, their Ozymandian builders otherwise long forgotten (Fig. 3).

On today's Mars, the Abode of Life is likeliest to be underground and cryptic, in deep liquid water aquifers that we hope exist. Of course we must still look for oases, but we cannot assume that we will find one. In some ways the debate has really moved little since the days of Flammarion and Lowell. The most interesting information remains right at the limit of resolution, be it metres in satellite images of gullies, or nanometres in microscopic images of magnetite crystals. Always life on Mars seems just beyond the fields that we know.

Things may have been different in the past, as they are likely to differ in the future. A key is space travel. Currently, traffic between Earth and Mars is fitful, accidental and expensive, depending mostly upon launching inadvertent microbionauts amongst a welter of impact ejecta, and then depending upon the vagaries of orbital dynamics to deliver the few survivors intact and alive to their new home. Today's Mars is too hostile to provide much hope that the surviving colonists could establish a viable self-sustaining ecosystem: habitable niches at the surface are likely to be so few, short-lived and widely separated that extinction seems the likeliest option, even were the first rock to land in a pond, while Mars' cryptic lakes would be unreachable, even if they exist.

In the deep past, such accidental traffic would have been much greater than today, and we have direct observational evidence that Mars was once a far more fit place to live. As it is not known why ancient Mars was in some average sense warmer and wetter than it is today, one cannot go much further into reconstructing the ancient island biogeography between planets. A plausible hope is that Mars still preserves on its surface evidence of a life that left Earth (or vice versa) more than 4 billion years ago. We cannot know this until we go.

The future, we can guess. Eventually earthlings will take Mars for their own. If there still remains at this late date indigenous life on Mars, it will be exterminated. No other course seems credible, our best intentions notwithstanding. Thus we might come to wish that Mars be now sterile, lest we add planetocide to our dictionaries.

"And before we judge of them too harshly, we must remember what ruthless and utter destruction our own species has wrought... The Tasmanians, in spite of their human likeness, were entirely swept out of existence in a war of extermination waged by European immigrants, in the space of fifty years. Arewe such apostles of mercy as to complain if the Martians warred in the same spirit?"

H. G. Wells The War of the Worlds

\footnotetext{
1. Lowell, P. Mars (Longmans, Green and Co., London, 1896).

2. Flammarion, C. La Planète Mars et Ses Conditions d'Habitabilité (Gauthier-Villars, Paris, 1892).

3. Sheehan, W. The Planet Mars (Univ. Arizona Press, Tucson, 1996).

4. Lowell, P. Mars and Its Canals (Macmillan, London, 1906).

5. Caidin, M. \& Barbree, J. Destination Mars (Penguin Studio, New York, 1997).

6. Hoyt, W. G. Lowell and Mars (Univ. Arizona Press, Tucson, 1976).

7. Lowell, P. Mars as an Abode of Life (Macmillan, London, 1908).

8. Horowitz, N. To Utopia and Back (Freeman, New York, 1986).

9. de Vaucouleurs, G. The Physics of the Planet Mars (Faber and Faber, London, 1954).

10. Kellogg, W. W. \& Sagan, C. The Atmospheres of Mars and Venus Publication 944 (National Academy of Sciences National Research Council, Washington DC, 1961).

11. Salisbury, F. B. Martian biology. Science 136, 17-26 (1962).

12. Sullivan, W. We Are Not Alone (McGraw Hill, New York, 1964).

13. Anders, E. \& Owen, T. Mars and Earth: origin and abundance of volatiles. Science 198, 453-465 (1977). 14. Glasstone, S. The Book of Mars (National Aeronautics and Space Administration, Washington DC, 1968). 15. Wallace, A. R. Is Mars Habitable? (Macmillan, London, 1907).
} 